\title{
Quartz Microbalance Sensor for the Detection of Acrylamide
}

\author{
Guido Kleefisch, ${ }^{1}$ Christian Kreutz, ${ }^{1}$ Joachim Bargon, ${ }^{1 *}$ Gabriele Silva ${ }^{2}$ and \\ Christoph A. Schalley ${ }^{2}$ *
}

${ }^{1}$ Institute of Physical und Theoretical Chemistry, University of Bonn, Wegelerstrasse 12, D-53115 Bonn, Germany

${ }^{2}$ Kekulé-Institute of Organic Chemistry and Biochemistry, University of Bonn, Gerhard-DomagkStr. 1, D-53121 Bonn, Germany

* Author to whom correspondence should be addressed.

Received: 30 June 2004 / Accepted: 22 September 2004 / Published: 1 Oktober 2004

\begin{abstract}
Several macrocycles of the Hunter-Vögtle type have been identified as superior host compounds for the detection of small amounts of acrylamide. When coated onto the surface of a quartz microbalance, these compounds serve as highly sensitive and selective sensor-active layers for their use in electronic noses. In this study, differently substituted macrocycles were investigated including an open-chain analogue and a catenane. Their structure and functional groups are correlated with their observed affinities to acrylamide and related acids and amides. The much smaller response of the open-chain compound and the almost absent sensor response of the catenane suggest that binding occurs within the cavity of the macrocycle. Theoretical calculations agree well with the experimental data even though they do not yet take into account the arrangement of the macrocycles in the sensor-active layer. The lower detection limit of acrylamide is 10 parts per billion (ppb), which is impressively low for this type of sensor. Other related compounds such as acrylic acid, propionamide, or propionic acid show no or significantly lower affinities to the macrocycles in these concentration ranges.
\end{abstract}

Keywords: Electronic noses, acrylamide, food analysis, tetralactam macrocycles, quartz microbalance sensors. 


\section{Introduction}

The interest in new simple sensor systems was again kindled by the recent controversial discussion concerning acrylamide and its role as a carcinogen in deep-fried foods. In animal experiments, Swedish scientists [1] had identified its carcinogenic potential and also had discovered it in food products. However, its effect on humans is still under debate. Thus, a team of the Karolinska Institute [2] in Stockholm analyzed a population study a second time, which examined the eating habits of cancer patients as compared to those of healthy persons. In contrast to the animal experiments, no significant differences between the two groups were found.

A possible pathway for the formation of acrylamide in food is the Strecker decomposition of the natural amino acid asparagine (Figure 1) [3]. This reaction takes place at high temperatures, e.g. when roasting or deep-frying potatoes. Although not all biochemical reaction steps leading from asparagine to acrylamide have been fully uncovered, this reaction likely proceeds via a transaminationdecarboxylation sequence that yields the Strecker aldehyde. Listings of quantities of acrylamide in food are, for example, supplied by several consumer associations [4].

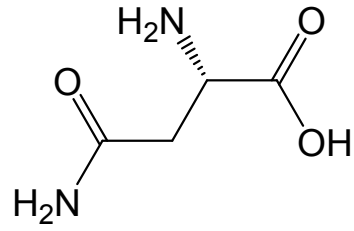

asparagine<smiles>[R]C(=O)C([R])=O</smiles><smiles>O=C1CCCCC1</smiles>

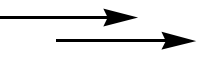<smiles>NC(=O)CC=O</smiles><smiles>[R]C(=O)C([R])N</smiles>

Strecker aldehyde<smiles>C=CC(N)=O</smiles>

Figure 1. Strecker decomposition of asparagines.

Due to the possibly hazardous risks of acrylamide, the development of a sensor system is highly desirable, which is able to detect acrylamide in food products in both a cost-efficient and safe way. Electronic noses, like the quartz microbalance (QMB) [5] can make a significant contribution to solving this problem as they are an alternative to more complex and cost-intensive methods, like GC/MS. The QMB can be used for the detection of minute changes of masses at its surface, when a sensitive compound (host) as a top coating interacts with an analyte (guest) [6]. The resonance frequency of the oscillating quartz chip is lowered when its mass increases due to guest binding.

Earlier, tetralactam macrocycles of the Hunter/Vögtle-type have been shown to qualify as highly sensitive and selective sensor-active layers for the detection of carbonyl compounds [7]. These macrocycles can be synthesized according to well-established literature procedures [8] starting from the appropriately functionalized isophthalic acid dichloride, which is converted to the so-called "extended diamine" by reaction with diamine 1 (Figure 2). Macrocyclization can be afforded by addition of a second isophthalic acid dichloride under high-dilution conditions. Through this step-wise protocol, unsymmetrically substituted macrocycles such as 6 or 8 become readily available. The 
substituents $\mathrm{R}$ and $\mathrm{R}^{\prime}$ can be varied to a great extent. Changing the electron densities in the isophthalic acid moieties is known to have a large effect on the binding constants of amides in solution [9]. As a side-product, catenanes [10], i.e. two mechanically interlocked rings, are formed from most precursors through template synthesis [11]. One of them is included here for comparison.
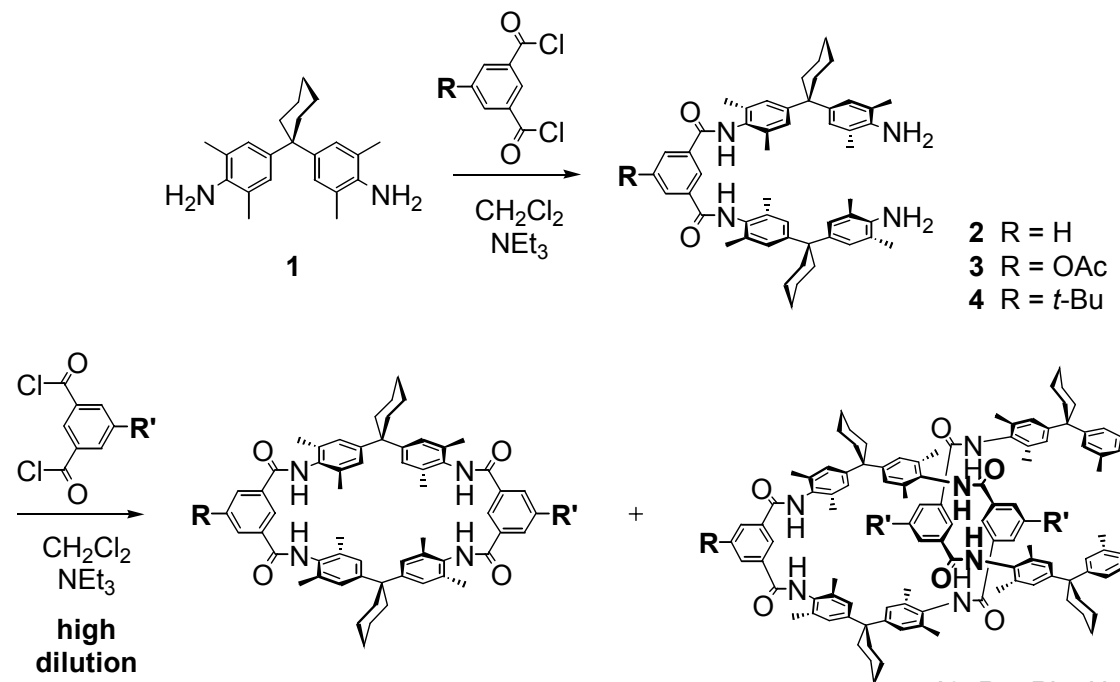

$$
\begin{array}{ll}
5 & R=R^{\prime}=H \\
6 & R=H, R^{\prime}=O M e \\
7 & R=R^{\prime}=O A c \\
8 & R=H, R^{\prime}=t-B u \\
9 & R=R^{\prime}=t-B u
\end{array}
$$

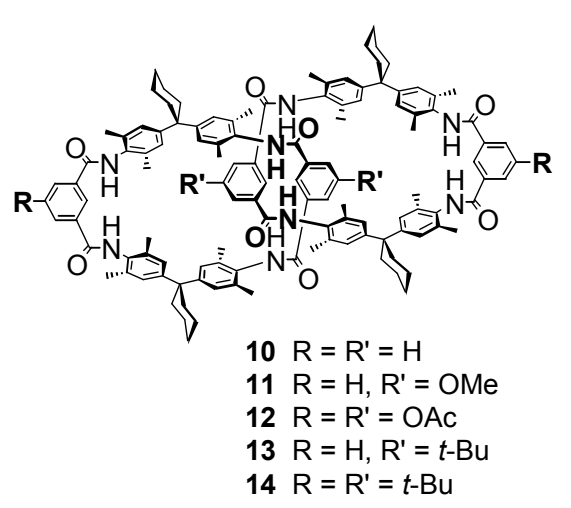

Figure 2. Synthesis of Hunter/Vögtle-type tetralactam macrocycles and the corresponding catenanes.

\section{Experimental set-up}

In order to provide exact concentrations of each analyte, a gas-mixing unit is used. For this purpose, a carrier gas, typically dry nitrogen, is led through a bubbler, which is filled with the analyte. According to the vapor pressures of the analytes, - the values are usually available from tabulated data [12] -, the nitrogen stream becomes enriched with the analyte and is subsequently fed into the measuring chambers. By means of condensers, the gas mixtures can be cooled to an exactly defined temperature, at which the analyte partly condenses so that its concentration in the gas stream is lowered to the desired value. During a measurement cycle the coated host material is exposed to different concentrations of an individual analyte.

The measuring chamber accommodates up to 24 quartz sensors at one time. Each of the latter consists of a thin quartz plate with gold electrodes deposited onto both sides. The top electrode was coated with the sensor-active material using the electrostatic spray method as known from electrospray mass spectrometry [13]. Briefly, the substance is dissolved in a polar solvent and transferred into a Hamilton syringe. Thereupon, a high voltage is applied between the needle of the syringe and the top electrode of the QMB. While the syringe is agitated by a computer-controlled step motor, the spray is accelerated by the electrostatic field towards the quartz, where it deposits on the electrode to yield a homogenous layer. By means of in-situ monitoring of the frequency of oscillation of the $10 \mathrm{MHz}$ quartzes, the coatings are being standardized to result in thicknesses corresponding to a frequency shift of $20 \mathrm{kHz}$ at a layer weight of $88 \mu \mathrm{g} / \mathrm{cm}^{2}$. The integrity of the macrocycles after deposition on the 
sensor quartz was checked by ESI mass spectrometry, which gave the same mass spectra for the compounds before and after the spray process.

The coated quartz plates are then transferred into the measuring chamber and exposed to the different analytes, i.e. the volatile organic compounds (VOCs). The sensor response is monitored by a computer-based data system.

\section{Results and discussion}

The Hunter-Vögtle macrocycles, as outlined in Figure 2, were examined as host material for the detection of acrylamide. Figure 3 shows a typical sensor response to acrylamide as the guest at different analyte concentrations. Even at concentrations of acrylamide as low as $10 \mathrm{ppb}$ the sensor yields a well detectable signal.

The analogous results for the other macrocycles are summarized in Figure 4 as their frequency/concentration profiles. A steeper increase of the signal at increasing concentrations indicates a more potent sensor material.

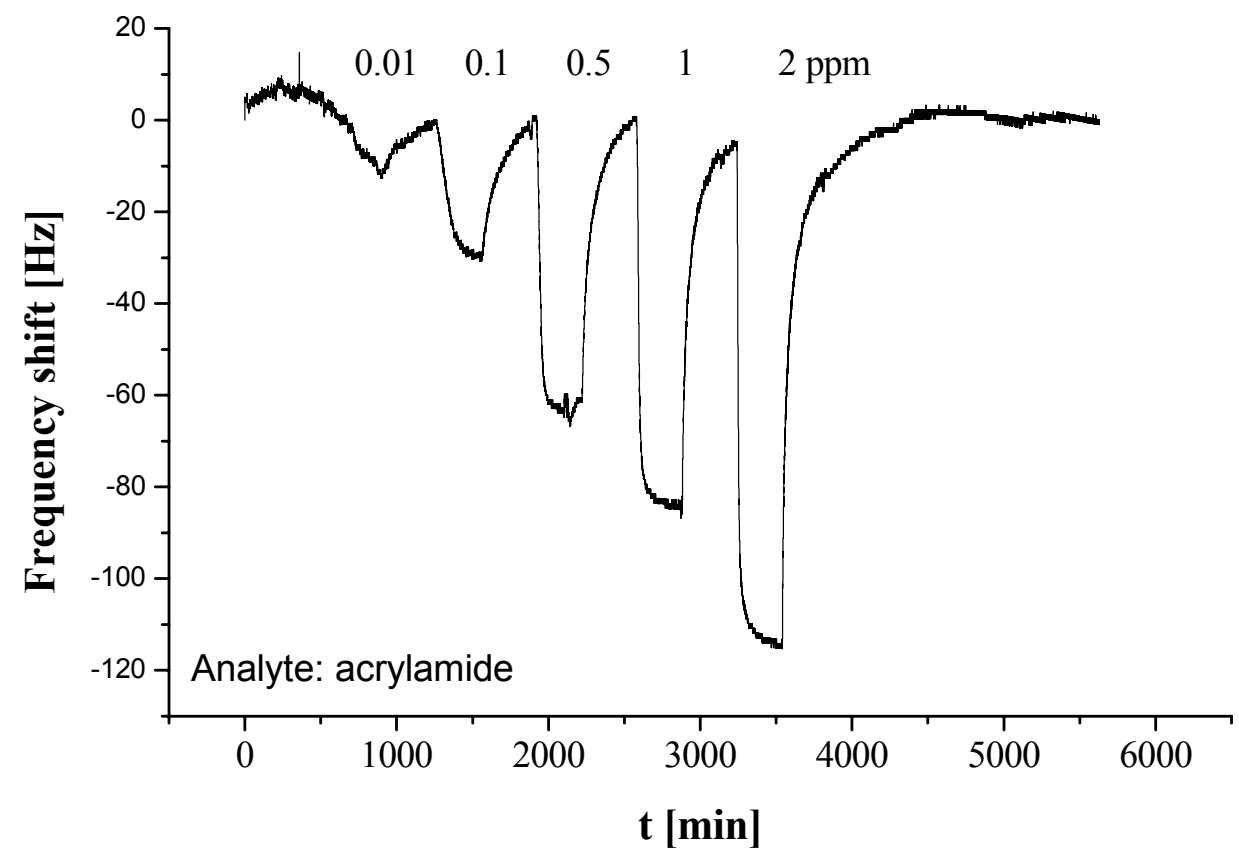

Figure 3. Sensor response of a QMB quartz coated with 9 to a series of increasing acrylamide concentrations.

As can be seen, 2 results in the smallest frequency shift when exposed to acrylamide. In marked contrast, 6 causes the highest frequency change among the hosts examined in this study. Both differ structurally only by the fact that the structure of 2 is open, while 6 exhibits a closed ring. This result prompted us to examine other related compounds such as 10, 2, 6 (Fig. 2), and 11 (Fig. 5 and Fig. 6) 


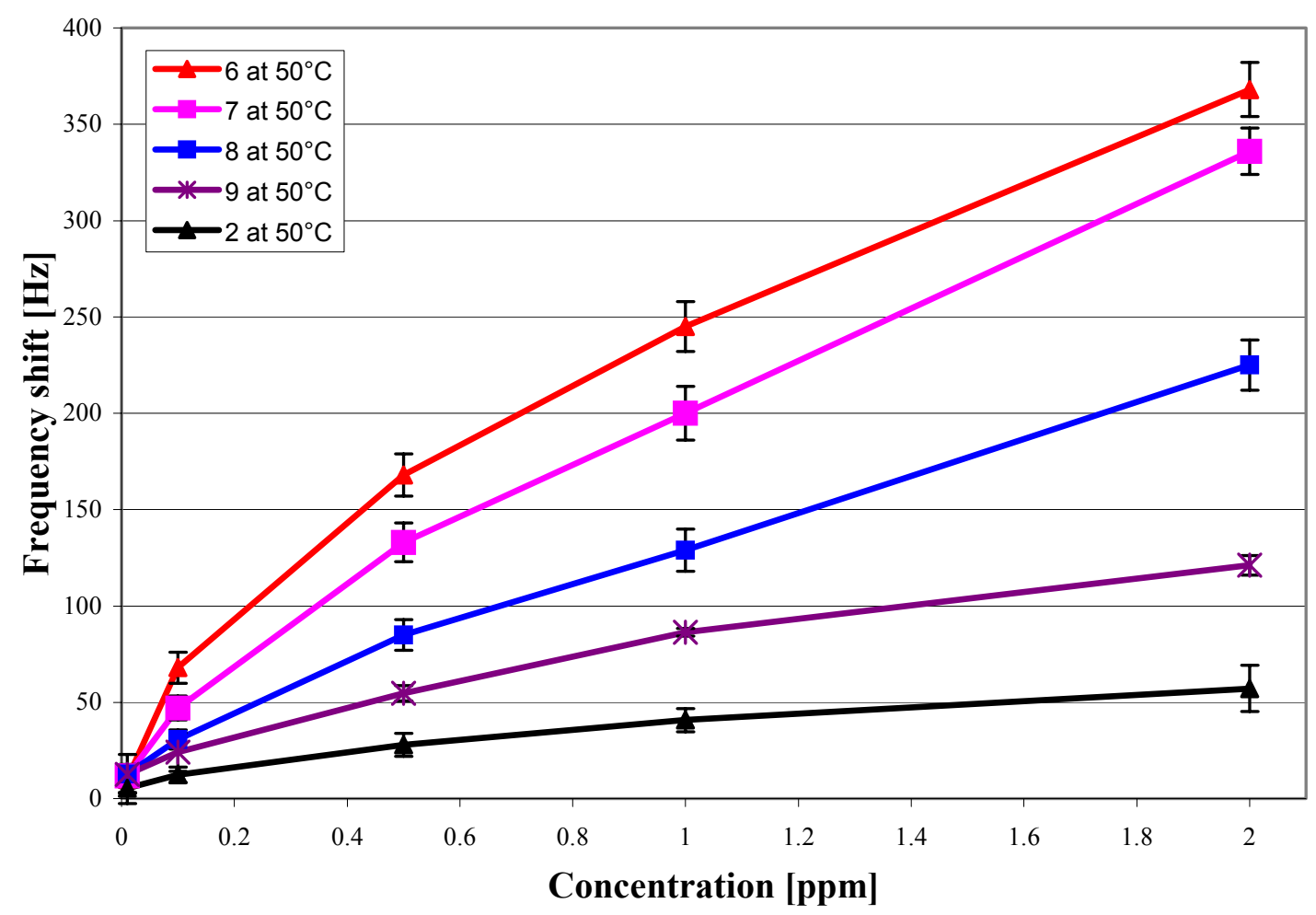

Figure 4. Characteristic frequency difference/concentration profiles of the tetralactam macrocycles 6 - 9 examined in this study including the open-chain extended diamine 2.

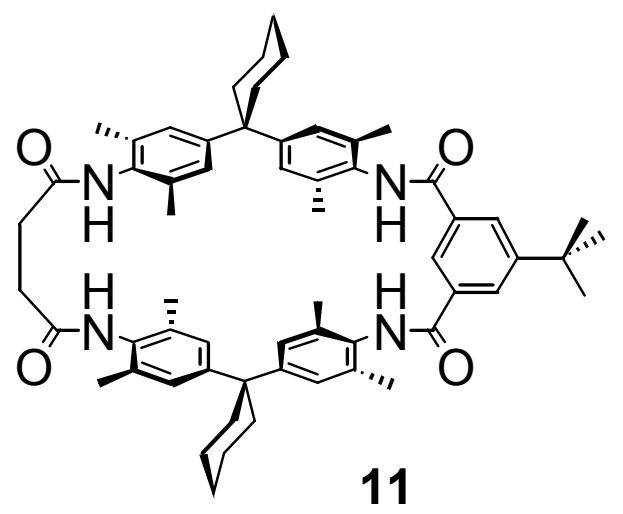

Figure 5. Macrocycle 11 bearing a non-aromatic diamide on one side.

By analyzing the characteristic responses, again the closed macrocycles, i.e. 11 and 6, are favored over the open-chain analogue 2, which likely exists in an extended conformation. The latter seems unfit for the assumed formation of the likely hydrogen bonds between the analyte and the macrocycles 11 and 6 [14]. The catenane 10, whose cavities are mutually blocked by the other wheel, shows practically no sensitivity to acrylamide. These findings lead to the conclusion that an interaction of the macrocycles with acrylamide takes place within the cavity.

Next, the quartzes coated with 2 and 9 were exposed to propionic amide, acrylic acid, and propionic acid, and the results are compared to those of acrylamide (Figs. 7 and 8). 


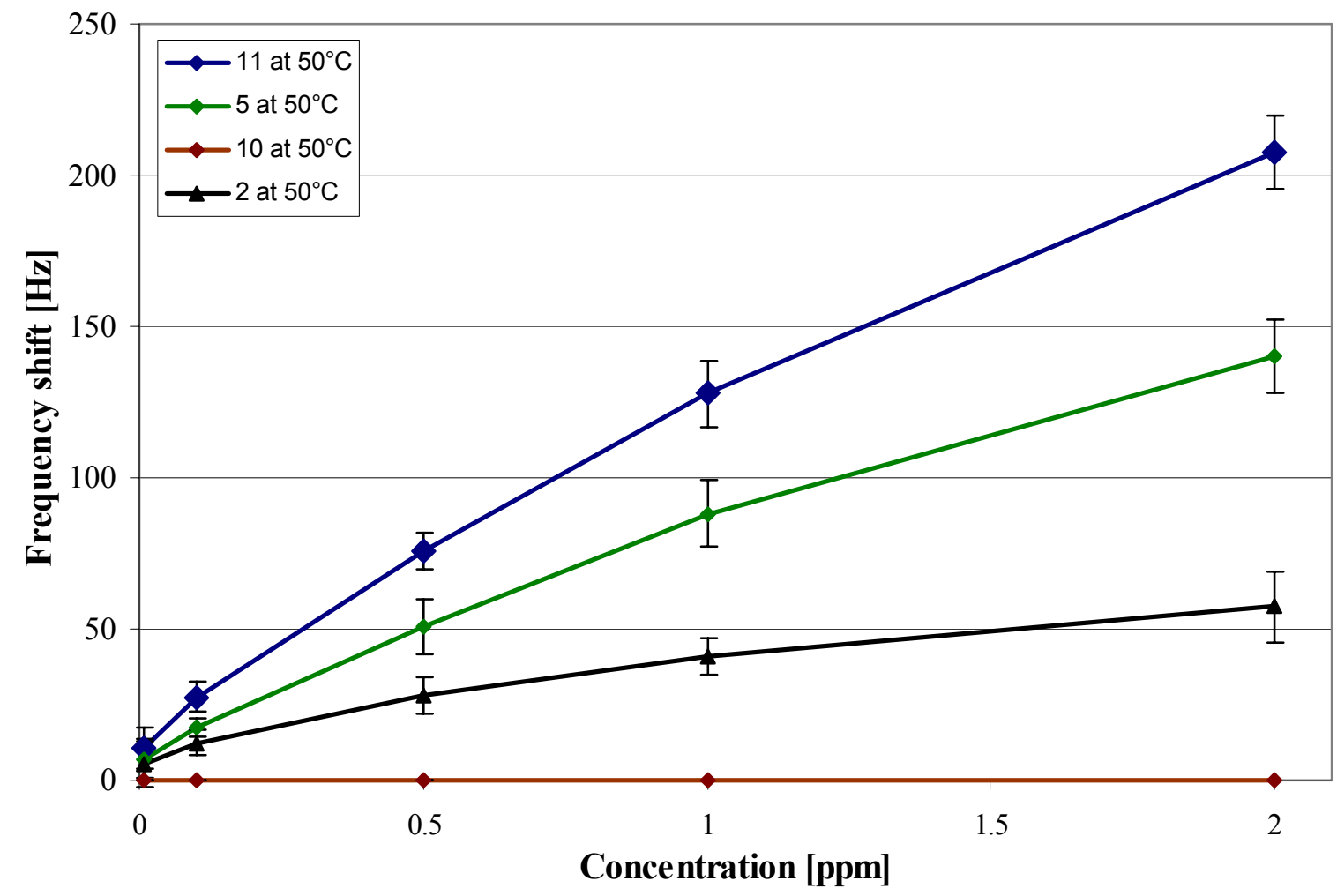

Figure 6. Characteristic lines of hosts with different ring forms.

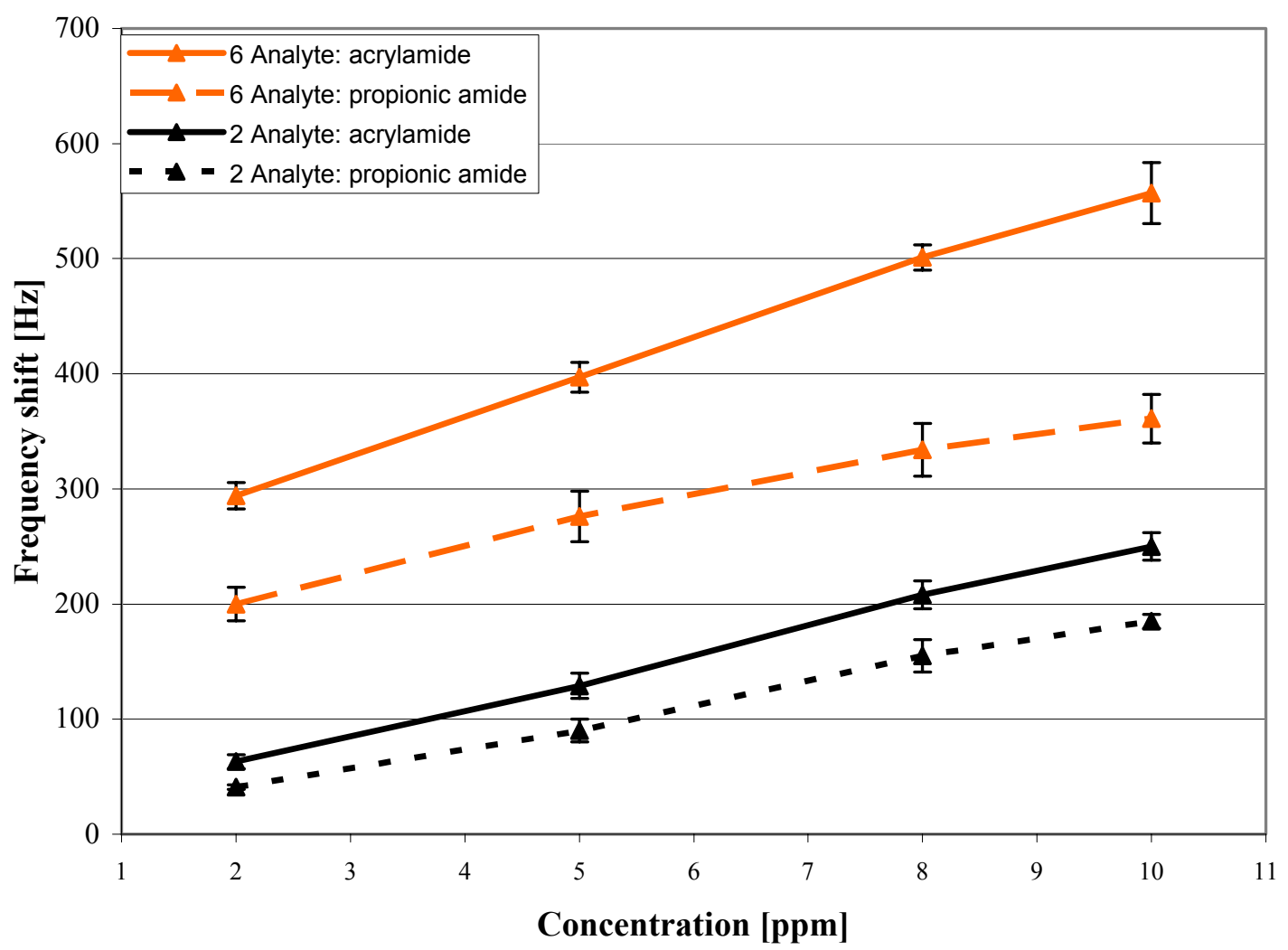

Figure 7. Characteristic responses of the analytes acrylamide and propionamide. 


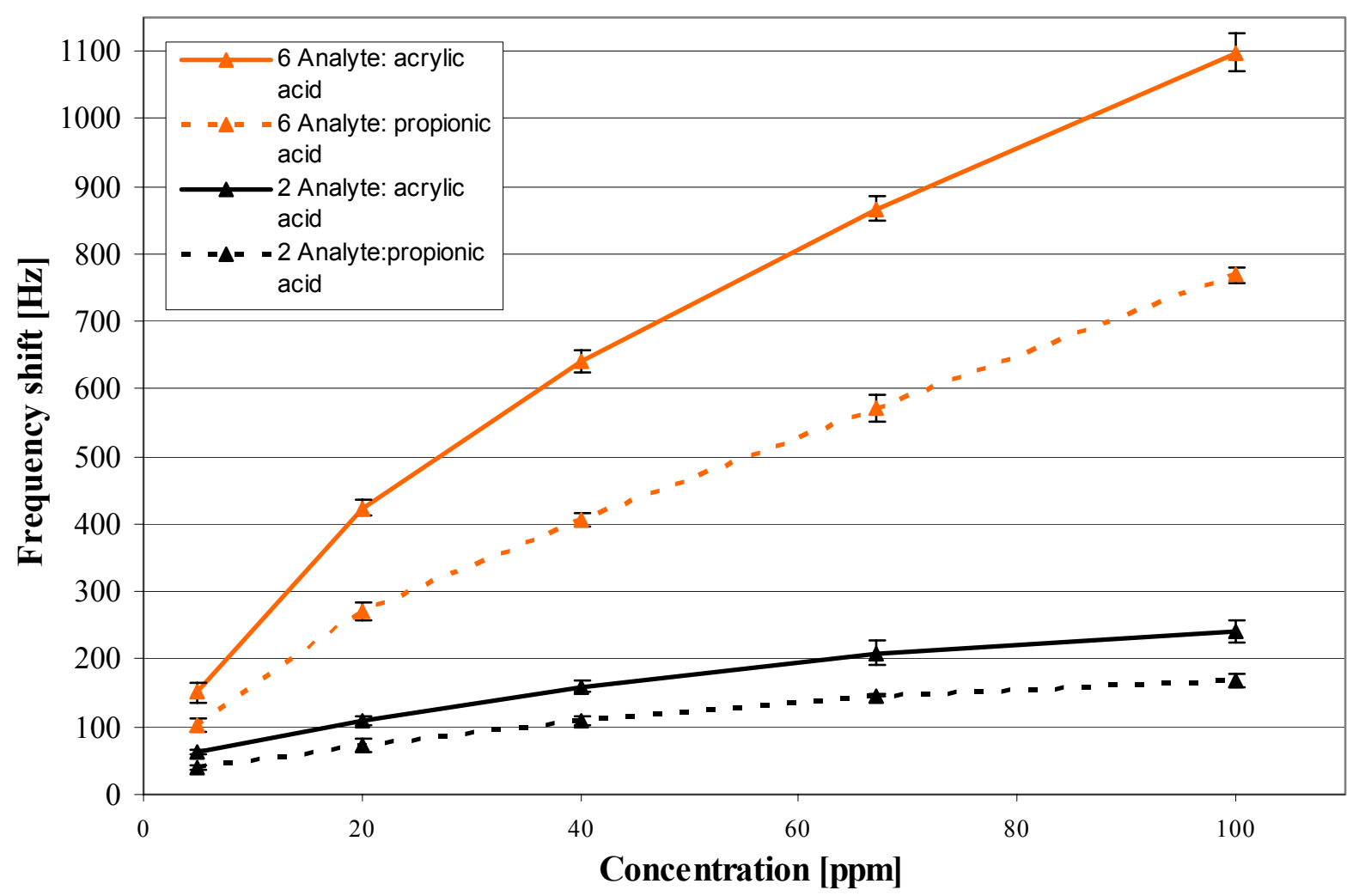

Figure 8. Characteristic responses of the analytes acrylic acid and propionic acid.

Since propionic acid exhibits no sensor response at concentrations lower than $1 \mathrm{ppm}$, and as the low vapor pressure of acrylamide only allows a maximum concentration of $10 \mathrm{ppm}$ at ambient temperature in our apparatus, the frequency shifts of the acids and amides are most easily compared at analyte concentrations of 5 ppm. Here, host 6 shows a frequency shift of $397 \mathrm{~Hz}$ for acrylamide, whereas the sensor response of $276 \mathrm{~Hz}$ for propionic acid is lower by nearly a factor of 1.5. Upon exposition to $5 \mathrm{ppm}$ of acrylic acid, the signal $(152 \mathrm{~Hz})$ is even reduced by a factor of 2.5. Most interestingly, the difference between acrylamide and propionic amide $(31-38 \%)$ and that between acrylic acid and propionic acid (27 - 36\%) are of the same order of magnitude. This effect is also observed for host 2 and could reflect the influence of the additional double bond of acrylamide and acrylic acid. One might speculate that $\pi-\pi$ interactions with the aromatic rings of the macrocycles play some role.

Geometry optimizations of a number of different conformations of the unsubstituted macrocycle at the semi-empirical AM1 level of theory [15] show the tetralactam hosts to slightly favor an all-in conformation [16], in which all amide NH groups are oriented into the macrocycle cavity. Nevertheless, conformations with one or two inverted amides, whose carbonyl groups point into the cavity, are calculated to be approximately $5 \mathrm{~kJ} / \mathrm{mol}$ above that of the all-in structure. Furthermore, the barriers for amide rotation are low so that it can safely be assumed that the macrocycles can easily adopt any of these conformations in solution. It is not quite clear, whether amide rotation may happen, once the sensor-active layer is sprayed onto the quartz surface and dried. Nevertheless, we have studied the binding of the four guests, i.e. acrylamide, acrylic acid, propionic acid, and propionic amide, to the unsubstituted tetralactam macrocycle assuming that it adopts the conformation most 
favorable for binding. All guests under study here are capable of forming a total of three hydrogen bonds to the macrocycle, when bound inside the cavity (Fig. 9). This pattern of hydrogen bonds has experimentally been confirmed through X-ray crystallography of rotaxanes and catenanes that were synthesized by a template effect utilizing amide binding inside their wheels [17].

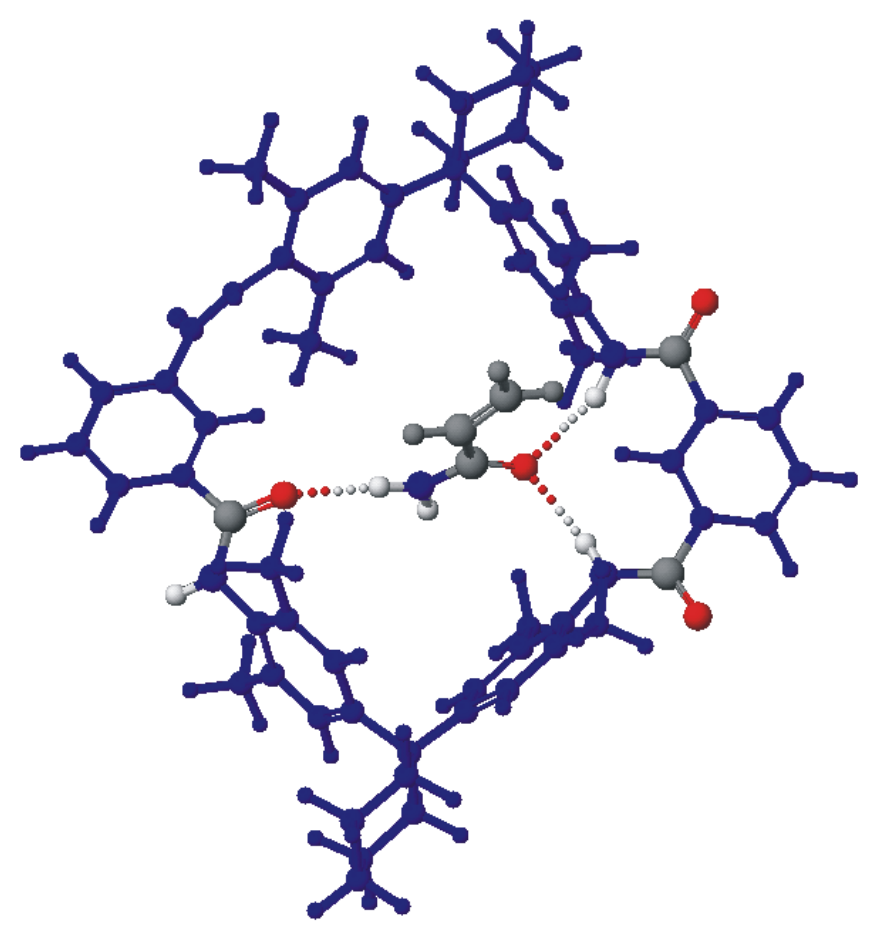

Figure 9. AM1-optimized structure of the complex of tetralactam macrocycle 5 with acrylamide.

The calculated AM1 binding energies $\left(\Delta H_{a s s o c}\right)$ are somewhat higher than those determined in dichloromethane solution for other similar amides, esters, ketones, and even acid chlorides [18]. However, since temperature-dependent measurements are currently not yet available, these experimental binding constants reflect the free binding enthalpies $\left(\Delta G_{\text {assoc }}\right)$ and thus, include entropic contributions. Consequently, they are not directly comparable; therefore, we can only state that the observed trends agree perfectly with those found in the experiment.

Simultaneous binding to more than one amide group at the periphery of the macrocycle outside its cavity is not likely and provides a lower binding energy. Likewise, binding of the analyte at interstitial cavities between the macrocycles is not likely either. This is underlined by the fact that there is no sensor response of the catenane, which should easily be able to form such interstitial cavities, while no open cavity inside the macrocycles is present. Clearly, the amides form stronger hydrogen bonds than the corresponding acids as is reflected in their respective binding energies (Table 1). Whereas, the acids bind with energies in the range of 16 to $18 \mathrm{~kJ} / \mathrm{mol}$, the amide binding strengths are calculated to be about twice as high (ca. 36 to $40 \mathrm{~kJ} / \mathrm{mol}$ ). This trend is in line with the measured association constants in solution and correlates well with the results obtained with the quartz microbalance. Here, the amides yield the highest frequency differences, while the acids show a lower frequency response. These calculated bonding properties agree well with the experimental results obtained. 
Table 1. Heats of formation $\Delta \mathrm{H}_{\mathrm{f}}$ and binding energies $\Delta \mathrm{H}_{\text {assoc }}$ of four different analyte molecules to the unsubstituted tetralactam macrocycle calculated at the AM1 level of theory.

\begin{tabular}{|c|c|c|c|}
\hline compound & macrocycle & $\Delta H_{f}(\mathrm{~kJ} / \mathrm{mol})$ & $\Delta H_{\text {assoc }}(\mathrm{kJ} / \mathrm{mol})$ \\
\hline \multicolumn{4}{|c|}{ single components } \\
\hline Acrylamide & & -102.8 & \\
\hline acrylic acid & & -321.0 & \\
\hline propionic amide & & -236.2 & \\
\hline propionic acid & & -456.0 & \\
\hline macrocycle 5 & all-in & -146.7 & \\
\hline & 3-in-1-out & -145.5 & \\
\hline & 2-in-2-out & -144.7 & \\
\hline \multicolumn{4}{|c|}{ macrocycle - analyte complexes } \\
\hline Acrylamide & 3-in-1-out & -292.6 & -36.4 \\
\hline acrylic acid & 3-in-1-out & -492.4 & -18.0 \\
\hline propionic amide & 3-in-1-out & -429.7 & -40.1 \\
\hline propionic acid & 3-in-1-out & -625.3 & -15.9 \\
\hline
\end{tabular}

\section{Conclusions}

In this work, the Hunter-Vögtle macrocycles could be identified as highly sensitive and selective coatings for the detection of acrylamide using gravimetric sensors. The lower detection limit of acrylamide is in the range of the maximum allowable concentration (MAC) of $10 \mathrm{ppb}$, which is impressively low for these commercially available quartz microbalances. Accordingly, these robust sensors provide for a cheap and easy to handle alternative to more expensive analytical methods such as GC-MS for monitoring concentrations of acrylamide down to its MAC-value.

Related compounds, like acrylic acid yield no signal in these concentration ranges, which clearly underlines the selectivity of the macrocycles used here. Comparison of analogous sensor materials with different topologies suggests acrylamide to be bound inside a cavity within the macrocycle. Further investigations concerning cross-sensitivities to typical compounds occurring in food products for measurements under ambient conditions are under investigation. First measurements of acrylamide in potato chips indicate no or a minor cross-sensitivity towards moisture. However, commercially available humidity sensors could be used to eliminate possible cross-sensitivities to water.

\section{Acknowledgement}

We thank Prof. Fritz Vögtle and Dr. Christiane Heim for providing us with a sample of macrocycle 11 and the Fonds der Chemischen Industrie as well as the Deutsche Forschungsgemeinschaft (SFB 624) for funding. C.K. is grateful to the Studienstiftung des Deutschen Volkes for a graduate fellowship. C.A.S. acknowledges the Deutsche Forschungsgemeinschaft for support with a Heisenberg fellowship and the Fonds der Chemischen Industrie for a Dozentenstipendium. 


\section{References}

1. http://www.netdoktor.de/feature/acrylamid.htm.

2. http://www.swisstox.net/de/news_d.php?st_lang_key=de\&st_news_id=1143.

3. http://www.wissenschaft-online.de/artikel/609380.

4. http://www.vzhh.de/ upload/vz/VZTexte/TexteErnaehrung/Acrylamid.htm.

5. Göpel, W. Chemische Sensoren - Technische Sinnesorgane für Riechen und Schmecken. Spektrum der Wissenschaft 1994, 1, 97.

6. Heil, C. Dissertation Universität Bonn, 2000.

7. a) Herrmann, U.; Jonischkeit, T.; Bargon, J.; Hahn, U.; Li, Q.-Y.; Schalley, C.A.; Vogel, E.; Vögtle, F. Monitoring apple flavor by use of quartz microbalances, Anal. Bioanal. Chem. 2002, 372, 611-614; b) Bargon, J.; Braschoß, S.; Flörke, J.; Herrmann, U.; Klein, L.; Lörgen, J.W.; Lopez, M.; Maric, S.; Parham, A.H.; Piacenza, P.; Schäfgen, H.; Schalley, C.A.; Silva, G.; Schwierz, H.; Vögtle, F.; Windscheif, G. Determination of the ripening state of Emmental cheese via quartz microbalances. Sensors \& Actuators B, 2003, 95, 6 .

8. a) Hunter, C.A. Molecular recognition of $p$-benzoquinone by a macrocyclic host, J. Chem. Soc., Chem. Commun. 1991, 749; b) Hunter, C. A. J. Synthesis and structure elucidation of a new 2catenane, Am. Chem. Soc. 1992, 114, 5303; c) Ottens-Hildebrandt, S.; Schmidt, T.; Harren, J.; Vögtle, F. Sulfonamid-based catenanes - regioselective template synthesis, Liebigs Ann. 1995, 1855; d) Jäger, R.; Händel, M.; Rissanen, K.;Vögtle, F. Chemistry with rotaxanes: intra- and intermolecularly covalenty linked rotaxanes, Liebigs Ann. 1996, 1201; e) Vögtle, F.; Jäger, R.; Händel, M.; Ottens-Hildebrandt, S.; Schmidt, W. Amide-based rotaxanes with terephthal, furan, thiophene and sulfonamide subunits, Synthesis, 1996, 353.

9. Chang, S.-Y.; Kim, H.S.; Chang, K.-J.; Jeong, K.-S. Efficient modulation of hydrogen-bonding interaction by remote substituents, Org. Lett, 2003, 6, 181.

10. a) Vögtle, F.; Meier, S.; Hoss, R. Templates, "wheeled reagents", and a new route to rotaxanes by anion complexation: The trapping method, Angew. Chem., 1992, 104, 1628; b) OttensHildebrandt, S.; Nieger, M.; Rissanen, K.; Rouvinen, J.; Meier, S.; Harder, G.; Vögtle F., Amidebased furano-catenanes: Regioselective template synthesis and crystal structure, J. Chem. Soc. Chem. Commun., 1995, 777.

11. a) Kogej, M.; Ghosh, P.; Schalley, C.A. How to thread a string into the eye of a molecular needle: Template-directed synthesis of mechanically interlocked molecules in: Strategies and Tactics in Organic Synthesis, M. Harmata (ed.), Elsevier, Amsterdam, 2004, vol. 4, 171-210. b) Schalley, C.A.; Weilandt, T.; Brüggemann, J.; Vögtle, F. Top. Curr. Chem., in press.

12. Weast, R.C. Handbook of Chemistry and Physics, The Chemical Rubber Co. Cleveland, Ohio, 1968, 49. Edn, D108. 
13. Iribarne, J.V.; Thomson, B.A. Evaporation of small ions from charged droplets, J.Chem.Phys., 1976, 64, 2287.

14. Linnartz, P.; Bitter, S.; Schalley, C.A. Deslipping of rotaxanes with axle center pieces of different lengths, Eur. J. Org. Chem., 2003, 4819.

15. Dewar, M. J. S.; Zoebisch, E. G.; Healy, E. F.; Stewart, J. J. P. Development and use of quantum mechanical molecular models. 76. AM1: a new general purpose quantum mechanical molecular model, J. Am. Chem. Soc., 1985, 107, 3902.

16. A validation of the AM1 semi-empirical method for the species under study was performed earlier: (a) Reckien, W.; Peyerimhoff, S. J. Phys. Chem. A 2003, 107, 9634. (b) Schalley, C. A.; Reckien, W.; Peyerimhoff, S.; Baytekin, B.; Vögtle, F. Chem. Eur. J., in press.

17. Reuter, C.; Seel,C.; Nieger, M.; Vögtle, F.; Chiral [1]Rotaxanes: X-Ray structures and chiroptical properties, Helv. Chim. Acta, 2000, 83, 630.

18. Seel, C.; Parham, A. H.; Safarowsky, O.; Hübner, G. M.; Vögtle, F. How selective threading of amides through macrocylic lactam wheels leads to rotaxane synthesis, J. Org. Chem., 1999, 64, 7236. 